Available online on 15.07 .2020 at http://jddtonline.info
Open Access to Pharmaceutical and Medical Research
unrestricted non-commercial use, provided the original work is properly cited

Open $\odot$ Access

Research Article

\title{
Antioxidant and antimicrobial effect of alkaloid bulbs extract of Polianthes tuberosa L. (Amaryllidaceae) cultivated in Algeria
}

\section{Nihed BARGHOUT ${ }^{*}$, Nada CHEBATA², Saida MOUMENE² ${ }^{2}$, Seddik KHENNOUF², Abdelaziz GHARBI², Djamel EL HADI ${ }^{3}$}

${ }^{1}$ Phytotherapy applied on chronic diseases Laboratory. Vegetal Biology and Ecology Department, Nature and Life Sciences Faculty. Setif-1 FERHET Abbas University. 19000. Setif, Algeria

${ }^{2}$ Aromatic and Medicinal Plants Laboratory. Biotechnology Department. Nature and Life Sciences Faculty. Blida 1 DAHLEB Saad University. 9000. Blida, Algeria

${ }^{3}$ Functional Analysis of Chemical Processes Laboratory, Process Engineering Department, Blida1 DAHLEB Saad University. 09000. Blida, Algeria

\begin{abstract}
Polianthes tuberosa L. (Amaryllidaceae) is an ornamental and medicinal plant. Its flowers and bulbs are used traditionally as a diuretic, emetic, against rashes and gonorrhea. The aim of this work was, to evaluate the antioxidant and antimicrobial activities of bulbs and bulbils alkaloid extracts of P. tuberosa. Antiradical effect was assessed against DPPH radical. However, antimicrobial activity was measured through the disc diffusion method against Escherichae coli ATCC 25922, Pseudomonas aeruginosa ATCC 27853, Staphylococcus aureus ATCC 25923, Enterococcus faecalis ATCC 29212, Staphylococcus aureus resistant to Methicillin (MRSA) and Candida albicans ATCC 90028. The scavenging effect against DPPH showed that the bulbs and bulbils alkaloids extracts exhibited an antiradical effect with $\mathrm{IC}_{50}=0.231 \pm 0.017 \mathrm{mg} / \mathrm{mL}$ and $0.233 \pm 0.093$ $\mathrm{mg} / \mathrm{mL}$ respectively, less than the effect of vitamin C with $\mathrm{IC}_{50}=0.0194 \pm 0.0002 \mathrm{mg} / \mathrm{mL}$. Antimicrobial activity results reveal that both alkaloid bulbs extracts at $50 \mathrm{mg} / \mathrm{mL}$ did not have any inhibitory effect against the studied strains using the disc diffusion method. According to this work, bulbs and bulbils alkaloid extracts show a moderate antioxidant effect; that could be recommended as a natural antioxid ant. Although tuberose bulbs were used traditionally as a soap substitute; bulbs alkaloid extract has no antimicrobial effect.
\end{abstract}

Keywords: Polianthes tuberosa L., bulbs, bulbils, alkaloids, antiradical activity, antimicrobial activity.

Article Info: Received 22 April 2020; Review Completed 16 June 2020; Accepted 23 June 2020; Available online 15 July 2020

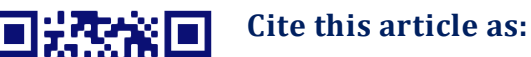

Barghout N, Chebata N, Moumene S, Khennouf S, Gharbi A, Gharbi A, El Hadi D, Antioxidant and antimicrobial effect of alkaloid bulbs extract of Polianthes tuberosa L. (Amaryllidaceae) cultivated in Algeria, Journal of Drug Delivery and Therapeutics. 2020; 10(4):44-48 http://dx.doi.org/10.22270/jddt.v10i4.4134

\section{ㅁ. 2.7. *Address for Correspondence:}

Barghout Nihed: Laboratory of Phytotherapy applied on chronic diseases. Department of Vegetal Biology and Ecology, Faculty of Nature and Life Sciences. FERHET Abbas University Setif-1. 19000. Algeria

\section{INTRODUCTION}

Oxidative stress is an imbalance caused especially by an overproduction of free radicals, which plays a major role in the development of chronic and degenerative diseases such as cancer, arthritis, aging, autoimmune disorders, cardiovascular and neurodegenerative diseases ${ }^{1}$. To decrease the harmful effects of free radicals, synthetic antioxidants can be used. However, chemical antioxidants have suspected of being responsible for liver damage and carcinogenesis ${ }^{2}$. Therefore, research of natural molecules with an antioxidant effect is essential to fight on the one side against free radicals and anomalies, and on the other side, eliminate the toxic effect of chemical antioxidants. Besides, resistance of pathogenic bacteria against antibiotics become a big concern to fight contagious diseases, for this reason, and to avoid the use of chemicals antibiotic, plant and plant extracts are used against pathogenic microorganisms ${ }^{3}$.

Polianthes tuberosa L. (Amaryllidaceae) known in Algeria as Mesk eromi, is a perennial herb native to Mexico. It's cultivated as ornamental and for its intense fragrance used in the perfume industry. Tuberose floral scent has an excellent effect on the brain and heart, stimulating the right side of the brain through improving emotional, psychological, and artistic inspiration 4 . P. tuberosa L. flowers and bulbs are diuretics and emetics, used for rashes. Dry bulbs powder is used for gonorrhea. Due to the high concentration of sapogenin in their rhizomes and tuberous roots, P. tuberosa has been used as a soap substitute. It has been reported that Polianthes tuberosa bulb contain lycorine, an alkaloid that 
causes vomiting5. Nevertheless, study of tuberose alkaloids and their biological activities are very limited. The crude methanol extract of $P$. tuberosa L. bulb has an antioxidant, antimicrobial, cytotoxic, membrane stabilizing and thrombolytic activities ${ }^{6}$, spirostanols, polianthoside B and $\mathrm{C}$ and D-G, furostanols and saponin were isolated and identified from its bulbs 7,8 .

To the best of our knowledge, antioxidant and antimicrobial effects of $P$. tuberosa bulb alkaloid extract have not been reported yet. For this reason, the aim of this work was to evaluate the antioxidant especially antiradical effect and antimicrobial effect, to enhance $P$. tuberosa bulbs as natural antiradical and antimicrobial agents.

\section{MATERIAL AND METHODS}

\subsection{Reagents and chemical products}

All solvent and product used in experiments were of analytical rang, ethanol, methanol, hydrochloric acid $(\mathrm{HCl})$, diethyl ether, ammonia, ethyl acetate, Diphenyl-2picrylhydrazy (DPPH) and vitamin $\mathrm{C}$ were purchased from Sigma and Flucka companies.

\subsection{Bulb collection}

Bulbs of $P$. tuberosa L. were harvested from pot culture during autumn in November 2015 (at dormant stage) when all the leaves were dried ${ }^{9}$. The bulbs were washed to put out the peat, and kept clean in a dry place at $10-15^{\circ} \mathrm{C}$. The dormant stage is recommended for the extraction and analysis of alkaloids 10. Bulbs were partitioned into two groups according to their size bulbs (diameter $>1 \mathrm{~cm}$ ) and bulbils (diameter $\leq 1 \mathrm{~cm}$ ).

\subsection{Extract preparation}

Bulbs extract was prepared according to the method of Cahlíková et al.11; fresh bulbs (3x15 g) were extracted three times with ethanol $(50 \mathrm{~mL})$ at room temperature for $24 \mathrm{~h}$ (Figure1). The solvent was evaporated under reduced pressure and the residue was dissolved in $10 \mathrm{~mL} \mathrm{HCl}(2 \%)$. After removing of the neutral compounds with diethyl ether ( $3 \times 15 \mathrm{~mL})$, the extract was basified with $25 \%$ ammonia solution and the alkaloids were extracted with ethyl acetate (3x15 mL). The organic solvent was evaporated to dryness and the yield was calculated and expressed in percent.

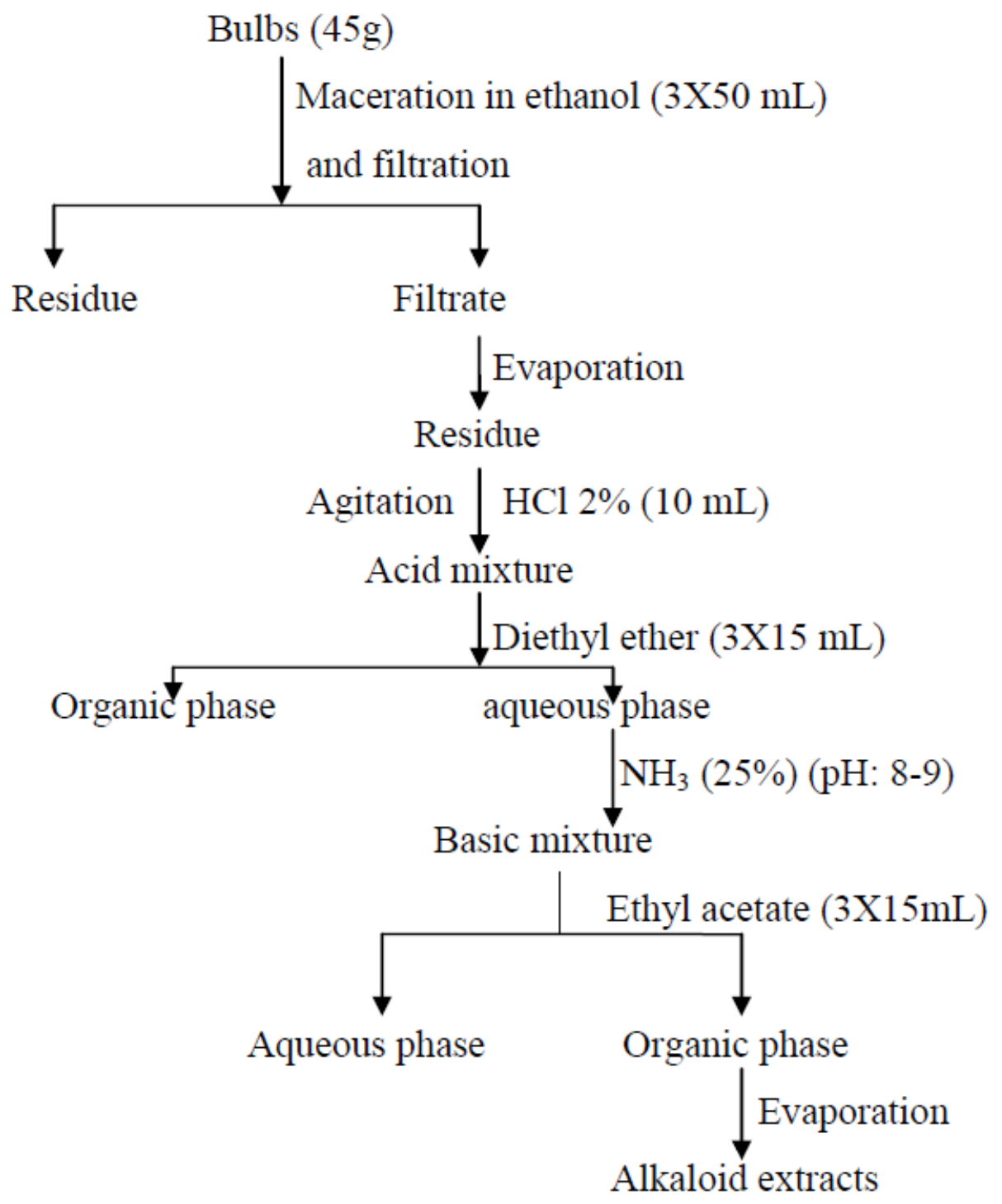

Figure 1: P. tuberosa bulbs alkaloids extraction steps. 


\subsection{Free radical scavenging test}

The antiradical activity against DPPH by alkaloid extracts of $P$. tuberosa L. bulbs was evaluated according to the method of Djarmoni et al. ${ }^{12}$ in Barghout et al. ${ }^{13}, 50 \mu \mathrm{L}$ of each different concentration of extracts $0.2-30 \mathrm{mg} / \mathrm{mL}$ (prepared in methanol) and vitamin $\mathrm{C}$ were mixed with $2.5 \mathrm{~mL}$ of the DPPH solution $(0.004 \%)$. After 30 minutes, absorbance was measured at $517 \mathrm{~nm}$. The percentage of inhibition (I\%) of the DPPH radical was calculated as follows:

$$
\mathrm{I} \%=100(\mathrm{AC}-\mathrm{AE} / \mathrm{AC})
$$

AC: Absorbance in the absence of the inhibitor (negative control).

$\mathrm{AE}$ : Absorbance in the presence of the inhibitor (extract and Vit C).

$\mathrm{IC}_{50}$ (50\% inhibitory concentration of DPPH activity) of each extract was calculated from the equation which determines the percent inhibition versus inhibitor concentration. It was expressed in $[\mathrm{mg} / \mathrm{mL}]$.

\subsection{Antimicrobial activity}

\section{a. Test microorganisms}

All microorganisms were obtained from bacteriology laboratory of Frantz Vanon hospital, Blida. The bacterial stains were Enterococcus faecalis ATCC 29212, Escherichae coli ATCC 25922, Pseudomonas aeruginosa ATCC 27853, Staphylococcus aureus ATCC 25923, Methicillin Resistant Staphylococcus aureus (MRSA) and yeast was Candida albicans ATCC 90028.

\section{b. Antimicrobial test}

The antimicrobial activity of P. tuberosa L. bulb extract was evaluated by agar disc diffusion method 14 . Bacteria were cultured on Muller-Hinton and the yeast was cultured on Sabouraud agar. Inoculums were prepared from $24 \mathrm{~h}$ old culture of microorganisms to $0.5 \mathrm{Mc}$ Farland turbidity. Once the agar on Petri dishes $(90 \mathrm{~mm})$ seeded by the prepared inoculums, discs of Whatman No.1 paper $(6 \mathrm{~mm}$ in diameter), were soaked, each, by a fixed volume of $10 \mu \mathrm{L}$ of alkaloid extracts. $50 \mathrm{mg} / \mathrm{mL}$ was the evaluated concentrations. Discs were deposited at equal distances on the surface of the agar. Discs impregnated with solvent were used as negative control 12 . After incubation of $24 \mathrm{~h}$ at $37^{\circ} \mathrm{C}$ for bacteria and $48 \mathrm{~h}$ for the yeast, all plates were observed for growth inhibition zones estimation, and the diameter of these zones was measured in millimeters.

\subsection{Statistical analysis}

Each experience was conducted three times and the results were presented as a means \pm standard deviation. Statistical analysis was done by one way ANOVA and student test using GraphPad 6.0 for Windows.

\section{RESULT AND DISCUSSION}

\subsection{Extract yield}

The alkaloid yield of the bulbs and bulbils of Polianthes tuberosa L. is expressed in percent (w/w fresh weight); the values were presented in Table 1 . It appears that the bulbs and bulbils from cultivated P. tuberosa are poor in alkaloids. Bulbs alkaloid extract amount was approximate to that of bulbils extract $(0.035 \%$ and $0.055 \%$ respectively). Indeed, it is important to note that a very limit works on the tuberose alkaloids have been reported in literature. Comparing results with other Amaryllidaceae plants, P. tuberosa bulbs alkaloid yield was lower than that of Rhodophiala mendocina (0.26\%), Habranthus jamesonii (0.27\%), Zephyranthes filifolia $(0.21 \%)$, and Habranthus jamesonii $(0.25 \%)$ bulbs alkaloids extracts 15 , these values are expressed refer to the dry mass of bulbs, neither to us, which may explain the difference with our results.

Table 1 : Yield and appearance of alkaloid extracts from bulbs and bulbils of $P$. tuberosa.

\begin{tabular}{lll}
\hline & Bulbs & Bulbils \\
\hline Yield (g/100g FM) & $0.035 \pm 0.005$ & $0.055 \pm 0.006$ \\
Extract appearance & Pale sticky paste & Pale sticky paste
\end{tabular}

Each value represents the mean \pm standard deviation $(n=3)$.

\subsection{Scavenging effect of $P$. tuberosa $L$. bulbs extract}

The discoloration degree of DPPH violet color solution indicates the free radical scavenging potentials of the antioxidant present in the plant extract. The antiradical activity of $P$. tuberosa L. bulb extract was presented in figure 2.

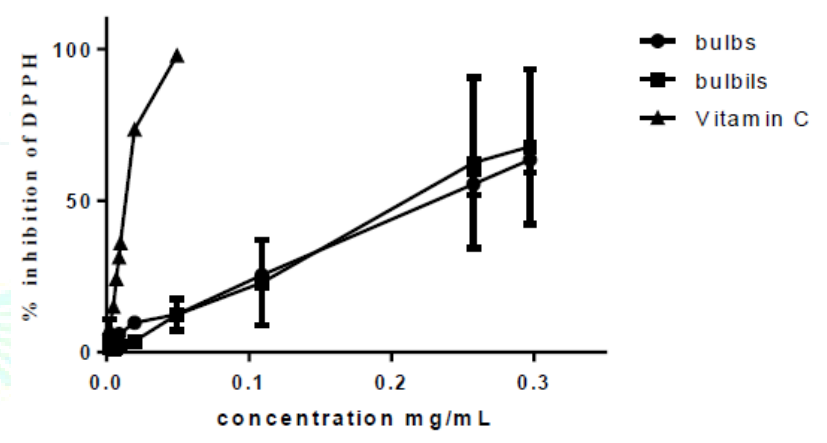

Figure 2: Inhibition percentage of free DPPH radical by Polianthes tuberosa bulbs, bulbils extracts and Vitamin C.

The scavenging effect of $P$. tuberosa bulbs extract on DPPH radical was dose-dependent manner, and the effect exhibited, was significantly close, bulbs to bulbils extracts ( $p>0.005)$. The antioxidant activity was determined through IC 50 values which are presented in figure 3.

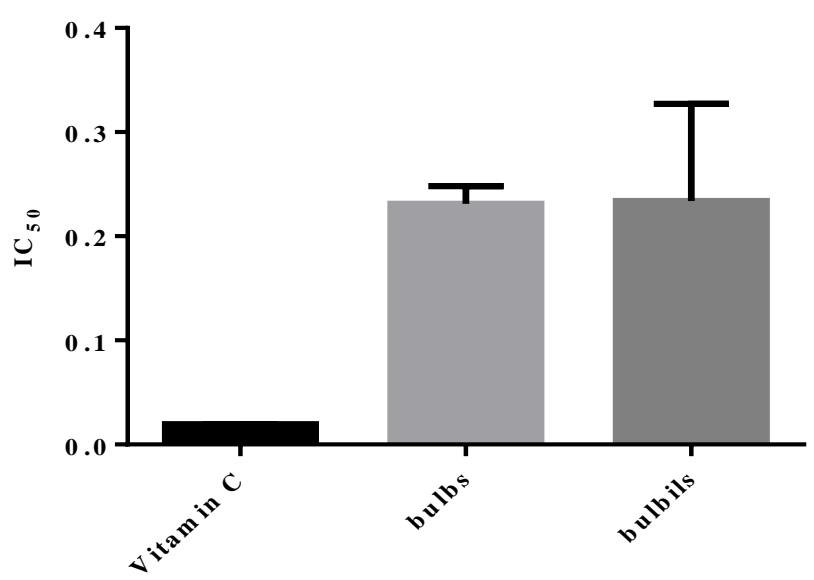

Figure 3: The $\mathrm{IC}_{50}$ against DPPH of bulbs, bulbils extracts and vitamin $C(p=0.01)$.

Based on the $\mathrm{IC}_{50}$ values, $\mathrm{IC}_{50}=0.231 \pm 0.017 \mathrm{mg} / \mathrm{mL}, 0.233$ $\pm 0.093 \mathrm{mg} / \mathrm{mL}$ and $0.0194 \pm 0.0002 \mathrm{mg} / \mathrm{mL}$ for bulbs, bulbils and vitamin $C$ respectively, there was no effect of the 
bulb size whether on the scavenging ability or on the minimal inhibitory concentration $(p>0.005)$, which was highly significantly less than vitamin $C(p<0.005)$. In general the bulb extract possessed a moderate antioxidant effect and this due to the Amaryllidaceae alkaloids presented in the extracts like lycorin which has been already reported, that it exhibits an antioxidant effect 16,17 . Our results were confirmed by the previous work on other Amaryllidaceae plants. Adewusi et al. ${ }^{18}$ report that the scavenging effect of ethyl acetate bulbs extract of Crinum bulbispermum and Scadoxus puniceus is less than $50 \%$ of radical scavenging using $0.125 \mathrm{mg} / \mathrm{mL}$ as high concentration. According to the work of Orhan et al. ${ }^{19}, 2000 \mu \mathrm{g} / \mathrm{mL}$ of ethyl acetate bulb extracts of Sternbergia candida, Sternbergia lutea subsp. lutea and Sternbergia lutea subsp. sicula present an antiradical effect less than $13 \%$, which is lower than $P$ tuberosa bulb extract effect at the same level. In the study of Castilhos et $a .^{20}$, the antioxidant activity of montanin (amaryllidaceae alkaloid type) is weak $36 \%$, at a concentration of $3.5 \mathrm{mg} / \mathrm{mL}$, which was even lower than $P$. tuberosa bulbs extract. Through this comparison, and even it is reported previously that bulb alkaloid extract have low scavenging effect, but $P$. tuberosa alkaloid bulb extract exhibited a strong scavenging effect at low concentrations.

\subsection{Antimicrobial activity}

Antimicrobial activity was evaluated by the famous agar diffusion method. Extracts were applied directly onto paper discs, which were then placed on the agar medium. The agar plates were incubated to allow the components of bulbs extracts to diffuse into the agar medium. The diameter of growth inhibition zones around the discs was then considered to be an indication of the effectiveness of the material being tested ${ }^{21}$. Our result for P. tuberosa L. bulbs and bulbils extracts, using $50 \mathrm{mg} / \mathrm{mL}$ concentration was negative. All the strains seemed to be resistance against both the extracts, their inhibition zone was $00.00 \mathrm{~cm}$ and positive antibiotics were: Ampicillin for E. coli with inhibition zone of $17 \mathrm{~mm}$, Penicillin was used against S. aureus and MRSA; its inhibition zones were $39 \mathrm{~mm}, 00.00$ respectively. Ceftazidin was used against $P$. aeruginosa and its inhibitory zone was $22 \mathrm{~mm}$. For E. faecalis, Gentamicine was used and its inhibitory zone was $19 \mathrm{~mm}$. For C. albicans yeast Cotrimoxazole and chloramphenicol were used and they do not show any inhibition effect.

From the present work, results indicated that neither tuberose bulbs extract had antimicrobial activity against all the microorganisms, at $50 \mathrm{mg} / \mathrm{mL}$ of concentration. The same tendency is obtained by Elgorashi et al. ${ }^{22}$ using 100 $\mathrm{mg} / \mathrm{mL}$ of bulb extract from plants belong to Amaryllidaceae family such as Gethyllis ciliaris, Cyrtanthus suaveolens, Cyrtanthus mackenii, Cyrtanthus falcatus against Bacillus subtilis, Escherichia coli, Klebsiella pneumoniae, Microccus luteus, Staphylococcus aureus. According to the work of Castilhos et $\mathrm{al}^{20}$, montanin at $1 \mathrm{mg} / \mathrm{mL}$ does not show an inhibitory effect against Micrococcus luteus (ATCC 9341) and Candida albicans (ATCC 10231). However, it shows a significant effect against the rest studied strains, where the minimal inhibitory concentration is $20 \mu \mathrm{g} / \mathrm{mL}, 5 \mu \mathrm{g} / \mathrm{mL}, 15$ $\mu \mathrm{g} / \mathrm{mL}, 5 \mu \mathrm{g} / \mathrm{mL}$ and $10 \mu \mathrm{g} / \mathrm{mL}$ against Pseudomonas aeruginosa (ATCC 27853), Staphylococcus aureus (ATCC 6538), Staphylococcus epidermides (ATCC 12228), Escherichia coli (ATCC 25922) and against Saccharomyces cerevisiae (ATCC 2601) respectively, these result are not consistent with ours, which could be related to the antagonist effect in the alkaloid mixture extracts of tuberose bulbs and bulbils.

\section{CONCLUSION}

In conclusion, this study highlighted the antiradical and antimicrobial activities of Polianthes tuberosa L bulbs and bulbils extract, through DPPH test and disc diffusion method. The anti-radical effect was moderate and these results suggest that this plant extracts may be used in many applications to limit the chemical antioxidant uses. Besides, the antimicrobial activity of $P$. tuberosa L. bulb extracts seems not to be effective against studied strains. No inhibition effect on microorganism growth has been recorded, even at high concentrations. That could be related, perhaps to the experimental steps or solvents which are not appropriate. This work still preliminary, further studies are needed to determine the chemical composition of alkaloids in P. tuberosa L. bulbs and bulbils extracts and studied their biological activities. Moreover, in vivo studies are recommended to more understand the mechanism of action of biological activity and possible cytotoxicity.

\section{Conflict of interest}

Author declares no conflict of interest

\section{Acknowledgement:}

This work was financed by the Algerian Minister of High Education and Scientific Research.

\section{REFERENCES}

1. Shinde A., Ganu J., Naik P. Effect of free radicals \& antioxidants on oxidative stress: A review. J. Dent. Allied Sci., 2012; 2:63-66.

2. Chaouche T.M., Haddouchi F., Ksouri R., Medini F., Atik-Bekara F In vitro evaluation of antioxidant activity of the hydromethanolic extracts of Juniperus oxycedrus subsp. oxycedrus. Phytothérapie, 2013; 11: 244-249.

3. Ben Hsouna A., Hamdi N., Ben Halima N., Abdelkafi S. Characterization of essential oil from Citrus aurantium $\mathrm{L}$. flowers: antimicrobial and antioxidant activities. J. Oleo. Sci., 2013; 62:763-772.

4. Wiart C. Medicinal plants of China, Korea, and Japan. Bioresources for tomorrow's drugs and cosmetics. CRC Press Taylor \& Francis Group, USA, 2012. P. 155-165.

5. Lim T.K.. Edible medicinal and non-medicinal plants. New York, London: Springer Dordrecht Heidelberg, 2014. P. 125-133.

6. Rumi F., Kuddus M.R., Chandra D. S. Evaluation of antioxidant, cytotoxic, antimicrobial, membrane stabilizing and thrombolytic activities of Polianthes tuberose Linn. British J. Pharma. Res., 2014; 4:2106-2115.

7. Mimaki Y., Yokosuka A., Sakuma C., Sakagami H., Sashida Y. Spirostanol pentaglycosides from the underground parts of Polianthes tuberosa. J. Nat. Prod., 2002; 65:1424-1428.

8. Jin J.M., Zhang Y.J., Yang C.R. Spirostanol and furostanol glycosides from the fresh tubers of Polianthes tuberosa. J. Nat. Prod., 2004; 67:5-9.

9. Gilly G.. Les plantes à parfum et huiles essentielles à Grasse. Botanique-Culture-Chimie-Production et marché; $1^{\mathrm{er}}$ ed France : L'Harmattan, 1997. P. 65-72.

10. Lopez S., Bastida J., Viladomat F., Codina C. Acetylcholinesterase inhibitory activity of some Amaryllidaceae alkaloids and Narcissus extracts. Life Sci., 2002; 71:2521-2529.

11. Cahlíková L., Valterová I., Macáková K., Opletal L. Analysis of Amaryllidaceae alkaloids from Zephyranthes grandiflora by GC/MS and their cholinesterase activity. Revis. Brasil. Farma. Brazil. J. Pharm., 2011; 21:575-580.

12. Djarmoni M., Boumerfeg S., Baghiani A., Boussoualim N., Zerargui F., Trabsa H., Belkhiri F., Khennouf S., Arrar L. Evaluation of antioxidant and antibacterial properties of Peganum harmala seed extracts. Res. J. Pharm. Biol. Chem. Sci., 2012; 3:1109-1119. 
13. Barghout N., Chebata N., Messgo-Moumene S., Khennouf S., Yekrelef A., El Hadi D. Polyphenols from Polianthes tuberosa L. (Amaryllidaceae) leaves and their antioxidant properties. Revue Agrobiologia, 2018; 8(1):902-912.

14. Ghedadba N., Bousselsela H., Hambaba L., Benbia S., Mouloud Y. Évaluation de l'activité antioxydante et antimicrobienne des feuilles et des sommités fleuries de Marrubium vulgare L. Phytothérapie, $2014 ; 1: 15-24$.

15. Ortiz J.E., Berkov S., Pigni N.B., Theoduloz C., Roitman G., Tapia A., Bastida J., Feresin G.E.. Wild argentinian Amaryllidaceae, a new renewable source of the acetylcholinesterase inhibitor galanthamine and other alkaloids. Molecules, 2012; 17:1347313482.

16. Giordani R.B., Pagliosa L.B., Henriques A.T., Zuanazzi J.A.S.. Investigação do potencial antioxidante e anticolinesterásico de Hippeastrum (amaryllidaceae). Quim. Nova., 2008; 31:20422046.

17. Ilavenil S., Kaleeswaran B., Ravikumar S.. Antioxidant and Hepatoprotective activity of lycorine against Carbon tetrachloride-induced oxidative stress in Swiss albino mice. Der. Pharma. Chemica., 2010; 2:267-272.
18. Adewusi E.A., Steenkamp V.. In vitro screening for acetylcholinesterase inhibition and antioxidant activity of medicinal plants from southern Africa. Asian Pacific J. Trop. Med., 2011; 1:829-835.

19. Orhan I.E., Yilmaz B.S., Altun M.L., Saltan G., Sener B. AntiAcetylcholinesterase and Antioxidant Appraisal of the Bulb Extracts of Five Sternbergia Species. Records of Natural Product, 2011; 5(3):193-201.

20. Castilhos T.S., Giordani R.B., Henriques A.T., Menezes F.S., Zuanazzi J.Â.S. Avaliação in vitro das atividades antiinfl amatória, antioxidante e antimicrobiana do alcalóide montanina. Brazilian J Pharm., 2007; 17(2):209-214.

21. Voon H.C., Bhat R., Rusul G.. Flower Extracts and Their Essential Oils as Potential Antimicrobial Agents for Food Uses and Pharmaceutical Applications. Comprehensive Reviews in Food Science and Food Safety, 2012; 11:34-55.

22. Elgorashi E.E., van Staden J.. Pharmacological screening of six Amaryllidaceae species. Journal of Ethnopharmacology, 2004; 90:27-32. 